\title{
Penilaian Guru Terbaik SMP Tri Sakti Lubuk Pakam Menggunakan Metode Topsis
}

\author{
Mestiada Elprida Marpaung ${ }^{1}$, Anita Sindar RMS ${ }^{2}$ \\ 1,2STMIK Pelita Nusantara Medan, Indonesia \\ E-mail: ${ }^{1}$ mestiadamarpaung18@gmail.com, ${ }^{2}$ haito_ita@yahoo.com,
}

\begin{abstract}
Abstrak
Kompetensi guru mengalami perkembangan ke arah yang baik sehingga sulit memilih guru yang berprestasi menurut lembaga dan sulitnya menentukan prioritasnya. Ketidaktepatan dalam memberikan penilaian kinerja guru berdampak pada hasil keputusan yang tidak tepat. Aplikasi SPK menggunakan data, memberikan antarmuka pengguna yang mudah, dan dapat menggabungkan pemikiran pengambil keputusan. Konsep SPK merupakan sebuah sistem interaktif berbasis komputer yang membantu pembuatan keputusan memanfaatkan data dan model untuk menyelesaikan masalah-masalah yang bersifat tidak terstruktur dan semi terstruktur. Di dalam metode TOPSIS diperlukan perangkingan, dalam penelitian ini ditetapkan 5 kriteria : pelayanan/manajemen pendidikan, integritas/kejujuran, komitmen/konsistensi, dan kerjasama/ kepemimpinan. Hasil perhitungan TOPSIS dihasilkan Nilai preferensi (V) yang lebih besar menunjukan alternatif yang dipilih sebagai yang terbaik, hasil $\mathrm{V}$ data $1=0,371$, $\mathrm{V}$ data $2=0,371$, $\mathrm{V}$ data $3=0,438$, V data $4=0,440$, V data $5=0,30$. Nilai V terbesar : V data $4=0,440$, menjadi Guru Terbaik.
\end{abstract}

Kata kunci: Guru Terbaik, Perangkingan, SPK, TOPSIS

\section{Pendahuluan}

Penambahan tenaga guru mempengaruhi pengambilan keputusan untuk menentukan guru terbaik. SMP Tri Sakti Lubuk Pakam secara rutin melakukan penilaian kinerja rutin terhadap seluruh guru. Proses penilaian terhadap kinerja guru belum begitu detail (rinci), dan masih manual. Permasalahan muncul karena yang dinilai adalah subjektifitas masing-masing guru, sehingga penilaian yang diberikan masih tidak pasti. Pernyataan ini menggambarkan bahwa tugas pembinaan kemampuan guru menjadi tanggung jawab kepala sekolah, oleh karena itu kepala sekolah berkontribusi dalam program peningkatan profesionalisme mengajar guru dengan melibatkan semua unsur yang terkait. Meskipun banyak guru yang berprestasi dan profesional, namun masalah sesungguhnya terjadi pada fase rekomendasi guru yang akan mengikuti lomba guru berprestasi. Keputusan yang diambil diharapkan tidak subyektif agar kualitas yang diperoleh dapat sesuai dengan harapan sehingga tidak ada pihak yang dirugikan. Pengambilan keputusan untuk menetapkan apakah prestasi guru tersebut sudah memenuhi kualitas yang diterima atau tidak didasari beberapa kriteria yang ditetapkan oleh sekolah.

Sistem Pendukung Keputusan (SPK) atau Decision Support System (DSS) merupakan sistem informasi interaktif yang menyediakan informasi, pemodelan, dan pemanipulasian data [1]. Metode TOPSIS (Technique for Order Preference by Similarity to Ideal Solution) merupakan bagian dari SPK, mengambil keputusan terbaik berdasarkan permasalahan multikriteria. Solusi optimal dalam metode TOPSIS diperoleh dengan menentukan kedekatan relatif suatu alternatif terhadap solusi ideal positif. TOPSIS merangking alternatif berdasarkan prioritas nilai kedekatan relatif suatu alternatif terhadap solusi ideal positif [2]. Penerapan metode TOPSIS memutuskan seorang guru terbaik akan dilaksanakan dalam penelitian ini dengan menetapkan beberapa kriteria guru terbaik. Setiap kriteria diberi bobot penilaian [3]. 


\section{Tinjauan Literatur}

SPK dirancang untuk menunjang seluruh tahapan keputusan, yang dimulai dari tahapan mengidentifikasi masalah, memilih data yang relevan, menentukan pendekatan yang digunakan dalam proses pembuatan keputusan sampai pada kegiatan mengevaluasi pemilihan alternative [4].

\subsection{Langkah-Langkah Pemodelan SPK}

Pemodelan DSS dilakukan langkah-langkah sebagai berikut [5]:

1. Studi Kelayakan (Intelligence)

Pada langkah ini, sasaran ditentukan dan dilakukan pencarian prosedur, pengumpulan data, identifikasi masalah, identifikasi kepemilikan masalah, klasifikasi masalah, hingga akhirnya terbentuk sebuah pernyataan masalah.

2. Perancangan (Design)

Pada tahapan ini akan diformulasikan model yang akan digunakan dan kriteria-kriteria yang ditentukan. Langkah selanjutnya adalah memprediksi keluaran yang mungkin dan menentukan variabel-variabel model.

3. Pemilihan (Choice)

Pada tahapan ini akan dilakukan pemilihan modelnya, termasuk solusi dari model tersebut. Selanjutnya dilakukan analisi sensitivitas, yakni dengan mengganti beberapa variabel.

4. Membuat DSS

Setelah menentukan modelnya, selanjutnya mengimplementasikan dalam aplikasi DSS.

\subsection{Metode TOPSIS}

Setiap bobot kriteria ditentukan berdasarkan tingkat kepentingannya menurut pengambil keputusan. Langkah-langkah dari metode TOPSIS [6], [7]:

1. TOPSIS dimulai dengan membangun sebuah matriks keputusan.

Matriks keputusan X mengacu terhadap m alternatif yang akan dievaluasi berdasarkan $n$ kriteria. Matriks keputusan $\mathrm{X}$ :

$X=a 1:$ am $x 11 \cdots x 1 n: \because: x m 1 \cdots x m n$

ai $(\mathrm{i}=1,2,3, \ldots, \mathrm{m})$ adalah alternatif-alternatif yang mungkin, $x j(\mathrm{j}=1,2,3, \ldots, \mathrm{n})$ adalah atribut dimana performansi alternatif diukur, $x i j$ adalah performansi alternatif $a i$ dengan acuan atribute $x j$.

2. Membuat matriks keputusan yang ternormalisasi.

Persamaan yang digunakan untuk mentransformasikan setiap elemen $x i j$ adalah :

$r i j=x i j x i j 2 m i=1$

dengan $\mathrm{i}=1,2,3, \ldots, \mathrm{m} ;$ dan $\mathrm{j}=1,2,3, \ldots, \mathrm{n}$;

rij adalah elemen dari matriks keputusan yang ternormalisasi R. $x i j$ adalah elemen matriks dari keputusan X.

3. Membuat matriks keputusan yang ternormalisasi terbobot.

Dengan bobot $w i=w 1, w 2, w 3, \ldots, w n$ dimana $w j$ adalah bobot dari kriteria ke-j dan $w j=1 n j=1$ maka normalisasi bobot matriks $\mathrm{V}$ adalah :

$v i j=w j$ rij (3.3)

dengan $\mathrm{i}=1,2,3, \ldots, \mathrm{m} ;$ dan $\mathrm{j}=1,2,3, \ldots, \mathrm{n}$;

$v i j$ adalah elemen dari matriks keputusan yang ternormalisasi terbobot $\mathrm{V}$.

wij adalah bobot dari kriteria ke-j

rij adalah elemen dari matriks keputusan yang ternormalisasi R.

4. Menentukan matriks solusi ideal positif dan solusi ideal negatif. 
Solusi ideal positif dinotasikan $A+$, sedangkan solusi ideal negatif dinotasikan $A^{-}$. Berikut ini adalah persamaan dari $A+\operatorname{dan} A-$ :

a. $A+=(\max v i j j \in J), \min v i j j \in J^{\prime}, i=1,2,3, \ldots, m$

$=v 1+, v 2+, v 3+, \ldots, v n+$

b. $A^{-}=(\min v i j j \epsilon J), \max v i j j \in J^{\prime}, i=1,2,3, \ldots, m$

$=v 1-, v 2-, v 3-, \ldots, v n-$

$J=\{\mathrm{j}=1,2,3, \ldots, \mathrm{n}$ dan $\mathrm{J}$ merupakan himpunan kriteria keuntungan (benefit criteria) $\}$.

$J,=\{\mathrm{j}=1,2,3, \ldots, \mathrm{n}$ dan $J$, merupakan himpunan kriteria biaya (cost criteria) $\}$.

$v i j$ adalah elemen dari matriks keputusan yang ternormalisasi terbobot $\mathrm{V}$.

$v j+(\mathrm{j}=1,2,3, \ldots, \mathrm{n})$ adalah elemen matriks solusi ideal positif.

$v j-(\mathrm{j}=1,2,3, \ldots, \mathrm{n})$ adalah elemen matriks solusi ideal negatif.

a. $S+$ adalah jarak alternatif dari solusi ideal positif didefenisikan sebagai :

$S_{i}^{+}=\sqrt{\sum_{j=1}^{n}\left(v_{i j}-v_{j}^{+}\right)^{2}}$, dengan $\mathrm{i}=1,2,3, \ldots, \mathrm{m}$

b. $S$ - adalah jarak alternatif dari solusi ideal negatif didefenisikan sebagai :

$$
S_{i}^{-}=\sqrt{\sum_{j=1}^{n}\left(v_{i j}-v_{j}^{-}\right)^{2}} \text {, dengan } \mathrm{i}=1,2,3, \ldots, \mathrm{m}
$$

$\mathrm{Si}+$ adalah jarak alternatif ke-i dari solusi ideal positif,

$S i-$ adalah jarak alternatif ke-i dari solusi ideal negatif,

$v i j$ adalah elemen dari matriks keputusan yang ternormalisasi terbobot $\mathrm{V}$

$v j+$ adalah elemen matriks solusi ideal positif,

$v j-$ adalah elemen matriks solusi ideal negatif.

6. Menghitung kedekatan relatif terhadap solusi ideal positif.

Kedekatan relatif dari setiap alternatif terhadap solusi ideal positif dapat dihitung :

$$
c_{i}^{+}=\frac{s_{i}^{-}}{\left(s_{i}^{-}+s_{i}^{+}\right)}, 0 \leq c_{i}^{+} \leq 1
$$

dengan $\mathrm{i}=1,2,3, \ldots, \mathrm{m}$ dimana $\mathrm{ci}+$ adalah kedekatan relatif dari alternatif ke-i terhadap solusi ideal positif, $\mathrm{Si}+$ adalah jarak alternatif ke-i dari solusi ideal positif dan $\mathrm{Si}^{-}$adalah jarak alternatif ke-i dari solusi ideal negatif.

7. Meranking Alternatif.

Alternatif diurutkan dari nilai $\mathrm{C}+$ terbesar ke nilai terkecil. Alternatif dengan nilai $\mathrm{C}+$ terbesar merupakan solusi yang terbaik.

\section{Metodologi}

Pembuatan SPK metode TOPSIS memerlukan data dari ke-4 kriteria (disiplin, kerapian, kebersihan, dan tanggung jawab) dari beberapa sampel Guru yang nantinya akan diolah dengan menggunakan metode TOPSIS. Hasil yang diperoleh dari perhitungan metode TOPSIS berupa hasil perangkingan guru dengan nilai terbaik yang berhak untuk menerima pengangkatan jabatan/golongan agar dapat membantu pihak SMP Tri Sakti Lubuk Pakam dalam menentukan Guru yang berhak naik jabatan menjadi lebih tepat sasaran. 


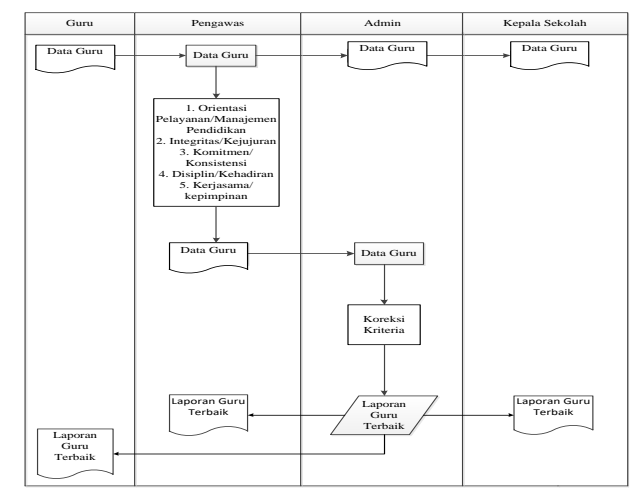

Gambar 1 : Bagan Alir Hasil Analisa Sistem

Activity diagram data calon Guru menggambarkan aktivitas admin dalam mengolah data calon Guru. Bentuk activity diagram calon guru terbaik, Gambar 2.

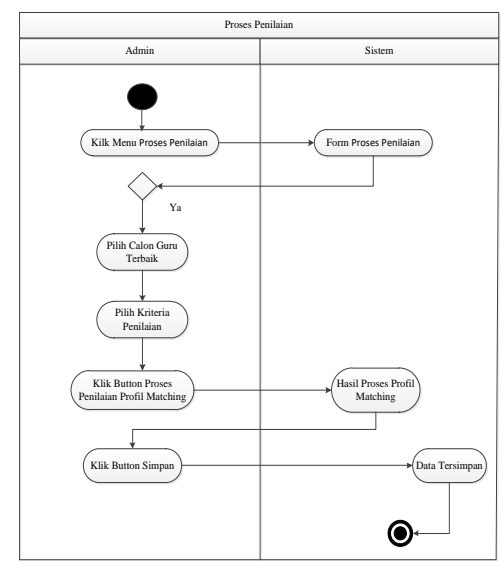

Gambar 2 : Activity Diagram Proses Penilaian

Sequence diagram proses penilaian menggambarkan interaksi antara admin dengan aplikasi dan database dalam melakukan penilaian penerimaan Guru. Bentuk sequence diagram proses penilaian dapat dilihat pada Gambar 3.

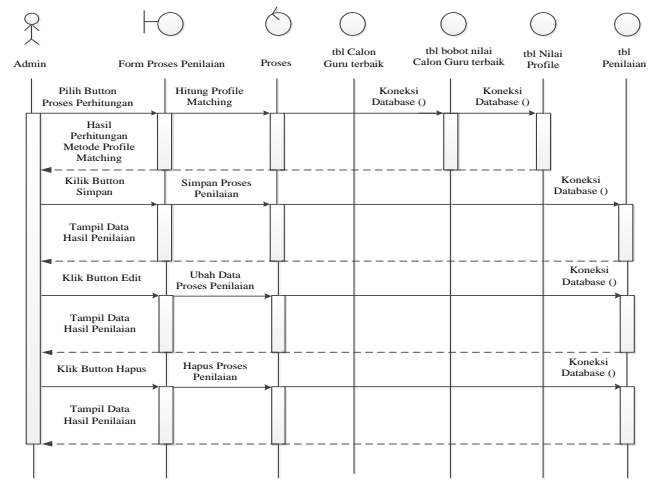

Gambar 3: Sequence Diagram Proses Penilaian

\section{Hasil dan Diskusi}

Mengamati beberapa formulasi pada analisis masalah maka ditawarkan untuk menyelesaikan rumusan-rumusan tersebut adalah menggunakan metode TOPSIS. 
Langkah-langkah penyelesaian metode TOPSIS adalah:

1. Membuat matriks keputusan yang ternormalisasi.

Rating kinerja alternatif $\mathrm{A} 1$ pada setiap kriteria $\mathrm{C} 1$ yang ternormalisasi :

$\left[X_{i}\right]=\sqrt{\sum_{i=1}^{m} X_{i j}^{2}}$

dengan $\mathrm{i}=1,2, \ldots, \mathrm{m}$ dan $\mathrm{j}=1,2, \ldots, \mathrm{n}$

$r_{i j=} \frac{x_{i j}}{\sqrt{\sum_{i=1}^{m} x_{i j}^{2}}}$

2. Membuat matriks keputusan yang ternormalisasi terbobot.

Solusi ideal positif dan solusi ideal negative dapat ditentukan berdasarkan rating bobot ternormalisasi (y) :

$y_{i j}=w_{i} r_{i j}$

$\mathrm{A}^{+}=\left(y_{1}^{+}, y_{2}^{+}, \ldots, y_{n}^{+}\right.$

$\mathrm{A}^{-}=\left(y_{1}^{-}, y_{2}^{-}, \ldots, y_{n}^{-}\right.$

$Y^{+}=\left\{\begin{array}{l}\max 1 Y i j \\ \min i Y i j\end{array}\right.$

$Y j^{-}=\left\{\begin{array}{c}\max i Y i j \\ \min i Y i j\end{array}\right.$

3. Menentukan matriks ideal positif dan matriks solusi ideal negatif.

$D_{i}^{+}=\sqrt{\sum_{j=1}^{n}\left(y_{i}^{+}-y_{i j}\right)^{2}}$

4. Menentukan jarak antara nilai setiap alternatif dengan matriks solusi ideal positif dan negatif.

$D_{i}^{-}=\sqrt{\sum_{j=1}^{n}\left(y_{i j}-y_{i}^{-}\right)^{2}}$

5. Menentukan nilai preferensi untuk setiap alternatif.

$\mathrm{V}=\frac{D i^{-}}{D i^{-}+D i^{+}}$

Nilai V yang lebih besar menunjukan alternatif yang dipilih sebagai yang terbaik.

Perangkingan Metode Topsis, akan dilakukan perangkingan dengan menggunakan metode Topsis, dalam penelitian ini akan digunakan beberapa data calon Guru terbaik Tabel 1.

Tabel 1 : Data Calon Guru Terbaik

\begin{tabular}{|c|c|c|c|c|c|}
\hline \multirow[b]{2}{*}{ Data } & \multirow[b]{2}{*}{ Nama Guru } & \multicolumn{4}{|c|}{ Kriteria } \\
\hline & & $\begin{array}{c}\text { Orientasi } \\
\text { Pelayanan/Manajemen } \\
\text { Pendidikan }\end{array}$ & $\begin{array}{c}\text { Integritas } \\
\text { /Kejujuran }\end{array}$ & $\begin{array}{c}\text { Komitmen } \\
\text { /Konsisten } \\
\text { si }\end{array}$ & $\begin{array}{c}\text { Kerjasama/ } \\
\text { Kepemimpin } \\
\text { an }\end{array}$ \\
\hline 1 & $\begin{array}{l}\text { Nurhati } \\
\text { Banjarnahor, S.Pd }\end{array}$ & 84 & 77 & 74 & 100 \\
\hline 2 & $\begin{array}{l}\text { Derita Debora } \\
\text { Sihaloho, S.Pd }\end{array}$ & 74 & 71 & 66 & 100 \\
\hline 3 & $\begin{array}{l}\text { Saur Pangaribuan, } \\
\text { S.Pd }\end{array}$ & 79 & 88 & 80 & 65 \\
\hline 4 & $\begin{array}{l}\text { Siti Asiyah } \\
\text { Batubara, S.Ag }\end{array}$ & 89 & 77 & 84 & 60 \\
\hline 5 & $\begin{array}{l}\text { Meryaty Rouli } \\
\text { Marbun, S.Pd }\end{array}$ & 90 & 79 & 74 & 10 \\
\hline
\end{tabular}

Bobot preferece yang digunakan adalah $\mathrm{W} 1=15 \%, \mathrm{~W} 2=15 \%, \mathrm{~W} 3=20 \%, \mathrm{~W} 4=30 \%$, dan $\mathrm{W} 5$ $=20 \%$. Perhitungan TOPSIS dari setiap Kandidat Guru :

a. Nurhati Banjarnahor,S.Pd. 
Tabel 2 : Penilaian TOPSIS Data 1

\begin{tabular}{|c|c|c|}
\hline $\begin{array}{l}\text { Matriks keputusan } \\
\text { yang ternormalisasi }\end{array}$ & \multicolumn{2}{|c|}{$\begin{array}{l}|X|=190,740 \\
R 1=0,419 R 2=0,403 R 3=0,387 R 4=0,524 R 5=0,466\end{array}$} \\
\hline $\begin{array}{l}\text { Matriks keputusan yang } \\
\text { ternormalisasi terbobot }\end{array}$ & $\begin{array}{l}\mathrm{Y}_{1}=\mathrm{W}_{1} * \mathrm{R}_{1}=15 \% * 0,419=0,062 \\
\mathrm{Y}_{3}=\mathrm{W}_{3} * \mathrm{R}_{3}=20 \% * 0,387=0,077 \\
\mathrm{Y}_{5}=\mathrm{W}_{5} * \mathrm{R} 5=20 \% * 0,466=0,093\end{array}$ & $\begin{array}{l}\mathrm{Y}_{2}=\mathrm{W}_{2} * \mathrm{R}_{2}=15 \% * 0,403=0,060 \\
\mathrm{Y}_{4}=\mathrm{W}_{4} * \mathrm{R}_{4}=30 \% * 0,524=0,157\end{array}$ \\
\hline $\begin{array}{l}\text { Solusi ideal positif dan } \\
\text { solusi ideal negatif }\end{array}$ & $\begin{array}{l}\mathrm{y}^{+}=\max \{0.062,0.060,0.077,0.524,0 \\
\mathrm{y}^{-}=\min \{0.062,0.060,0.077,0.524,0\end{array}$ & $\begin{array}{l}093\}=0.157=\mathrm{A}^{+} \\
093\}=0.060=\mathrm{A}^{-}\end{array}$ \\
\hline \multicolumn{2}{|c|}{$\begin{array}{l}\text { Jarak antara nilai setiap alternatif dengan matriks solusi } \\
\text { ideal positif }\left(D^{+}\right) \text {dan matriks solusi ideal negatif }\left(D^{-}\right) \text {. }\end{array}$} & $\begin{array}{l}\mathrm{D}^{+}=\sqrt{0.157}=0,396 \\
\mathrm{D}^{-}=\sqrt{0.060}=0,224\end{array}$ \\
\hline Nilai preferensi -V & & $\mathrm{V}=\frac{\mathrm{D}^{-}}{\mathrm{D}^{-}+\mathrm{D}^{+}}=0.381$ \\
\hline
\end{tabular}

b. Derita Debora Sihaloho, S.Pd

Tabel 3 : Penilaian TOPSIS Data 2

\begin{tabular}{|c|c|c|}
\hline $\begin{array}{l}\text { Matriks keputusan } \\
\text { yang ternormalisasi }\end{array}$ & $\begin{array}{l}|X|=\sqrt{74}^{2}+71^{2}+66^{2}+100^{2}+89^{2} \\
|X|=174,636 \\
R 1=0,423 \text { R2 }=0,406 \text { R3 } 3=0,377 \text { R4 }=0,57\end{array}$ & $72 \mathrm{R} 5=0,429$ \\
\hline $\begin{array}{l}\text { Matriks keputusan } \\
\text { yang ternormalisasi } \\
\text { terbobot }\end{array}$ & $\begin{array}{l}\mathrm{Y}_{1}=\mathrm{W}_{1} * \mathrm{R}_{1}=15 \% * 0,423=0,663 \\
\mathrm{Y}_{3}=\mathrm{W}_{3} * \mathrm{R}_{3}=20 \% * 0,377=0,075 \\
\mathrm{Y}_{5}=\mathrm{W}_{5} * \mathrm{R} 5=20 \% * 0,429=0,085\end{array}$ & $\begin{array}{l}\mathrm{Y}_{2}=\mathrm{W}_{2} * \mathrm{R}_{2}=15 \% * 0,406=0,060 \\
\mathrm{Y}_{4}=\mathrm{W}_{4} * \mathrm{R}_{4}=30 \% * 0,572=0,171\end{array}$ \\
\hline $\begin{array}{l}\text { Solusi ideal positif dan } \\
\text { solusi ideal negatif }\end{array}$ & $\begin{array}{l}\mathrm{y}^{+}=\max \{0,063,0,060,0,075,0,171,0,08 \\
\mathrm{y}^{-}=\min \{0,063,0,060,0,075,0,171,0,08\end{array}$ & $\begin{array}{l}85=0,171=\mathrm{A}^{+} \\
85\}=0,060=\mathrm{A}^{-}\end{array}$ \\
\hline \multicolumn{2}{|c|}{$\begin{array}{l}\text { Jarak antara nilai setiap alternatif dengan matriks solusi } \\
\text { ideal positif }\left(D^{+}\right) \text {dan matriks solusi ideal negatif }\left(D^{-}\right) \text {. }\end{array}$} & $\begin{array}{l}\mathrm{D}^{+}=\sqrt{0,1368}=0,413 \\
\mathrm{D}^{-}=\sqrt{0,058}==0,244\end{array}$ \\
\hline Nilai preferensi -V & & $\mathrm{V}=\frac{\mathrm{D}^{-}}{\mathrm{D}^{-}+\mathrm{D}^{+}}=0,371$ \\
\hline
\end{tabular}

c. Saur Pangaribuan, S.Pd

Tabel 4 : Penilaian TOPSIS Data 3

\begin{tabular}{|c|c|c|}
\hline $\begin{array}{l}\text { Matriks keputusan } \\
\text { yang ternormalisasi }\end{array}$ & $\begin{array}{l}|X|=\sqrt{79}^{2}+88^{2}+80^{2}+65^{2}+80^{2} \\
|X|=176,096 \\
R 1=0,448 \text { R2 }=0,499 \text { R3 }=0,454 \text { R4 }=0,3\end{array}$ & $9 \mathrm{R} 5=0,454$ \\
\hline $\begin{array}{l}\text { Matriks keputusan } \\
\text { yang ternormalisasi } \\
\text { terbobot }\end{array}$ & $\begin{array}{l}\mathrm{Y}_{1}=\mathrm{W}_{1} * \mathrm{R}_{1}=15 \% * 0,448=0,067 \\
\mathrm{Y}_{3}=\mathrm{W}_{3} * \mathrm{R}_{3}=20 \% * 0,454=0,090 \\
\mathrm{Y}_{5}=\mathrm{W}_{5} * \mathrm{R} 5=20 \% * 0,454=0,090\end{array}$ & $\begin{array}{l}\mathrm{Y}_{2}=\mathrm{W}_{2} * \mathrm{R}_{2}=15 \% * 0,499=0,074 \\
\mathrm{Y}_{4}=\mathrm{W}_{4} * \mathrm{R}_{4}=30 \% * 0,369=0,110\end{array}$ \\
\hline $\begin{array}{l}\text { Solusi ideal positif dan } \\
\text { solusi ideal negatif }\end{array}$ & $\begin{array}{l}\mathrm{y}^{+}=\max \{0,067,0,074,0,090,0,110,0,0 \\
\mathrm{y}^{-}=\min \{0,067,0,074,0,090,0,110,0,0\}\end{array}$ & $\begin{array}{l}0\}=0,110=\mathrm{A}^{+} \\
0\}=0,067=\mathrm{A}^{-}\end{array}$ \\
\hline \multicolumn{2}{|c|}{$\begin{array}{l}\text { Jarak antara nilai setiap alternatif dengan matriks solusi } \\
\text { ideal positif }\left(\mathrm{D}^{+}\right) \text {dan matriks solusi ideal negatif }\left(\mathrm{D}^{-}\right) \text {. }\end{array}$} & $\begin{array}{l}\mathrm{D}^{+}=\sqrt{0,110}=0,331 \\
\mathrm{D}^{-}=\sqrt{0,067}=0,258\end{array}$ \\
\hline Nilai preferensi -V & & $\mathrm{V}=\frac{\mathrm{D}^{-}}{\mathrm{D}^{-}+\mathrm{D}^{+}}=0,438$ \\
\hline
\end{tabular}

d. Siti Asiyah Batubara, S.Ag

Tabel 5 : Penilaian TOPSIS Data 4

\begin{tabular}{|l|l|}
\hline Matriks keputusan & $|\mathrm{X}|={\sqrt{79^{2}}+77^{2}+84^{2}+60^{2}+92^{2}}^{2}$ \\
yang ternormalisasi & $|\mathrm{X}|=180,839$ \\
\hline
\end{tabular}




\begin{tabular}{|l|l|l|}
\hline & $\mathrm{R} 1=0,492 \mathrm{R} 2=0,425 \mathrm{R} 3=0,464 \mathrm{R} 4=0,331 \mathrm{R} 5=0,508$ \\
\hline $\begin{array}{l}\text { Matriks keputusan } \\
\text { yang ternormalisasi } \\
\text { terbobot }\end{array}$ & $\mathrm{Y}_{1}=\mathrm{W}_{1} * \mathrm{R}_{1}=15 \% * 0,492=0,073 \quad \mathrm{Y}_{2}=\mathrm{W}_{2} * \mathrm{R}_{2}=30 \% * 0,425=0,063$ \\
$\mathrm{Y}_{3}=\mathrm{W}_{3} * \mathrm{R}_{3}=15 \% * 0,464=0,092$ & $\mathrm{Y}_{4}=\mathrm{W}_{3} * \mathrm{R}_{3}=20 \% * 0,331=0,099$ \\
\hline $\begin{array}{l}\text { Solusi ideal positif dan } \\
\text { solusi ideal negatif }\end{array}$ & $\mathrm{y}^{+}=\mathrm{W}=\mathrm{W}_{5} * \mathrm{R} 5=20 \% * 0,508=0,101$ \\
\hline $\begin{array}{l}\text { Jarak antara nilai setiap alternatif dengan matriks solusi } \\
\text { ideal positif }\left(\mathrm{D}^{+}\right) \text {dan matriks solusi ideal negatif }\left(\mathrm{D}^{-}\right) .\end{array}$ & $\mathrm{D}^{+}=\sqrt{0,110}=0,331$ \\
\hline & $\mathrm{D}^{-}=\sqrt{0.063}=0,250$ \\
\hline Nilai preferensi -V & $\mathrm{V}^{-} \frac{\mathrm{D}^{-}}{\mathrm{D}^{-}+\mathrm{D}^{+}}=0,440$ \\
\hline
\end{tabular}

\section{d. Meryaty Rouli Marbun, S.Pd}

Tabel 6 : Penilaian TOPSIS Data 5

\begin{tabular}{|c|c|c|}
\hline $\begin{array}{l}\text { Matriks keputusan } \\
\text { yang ternormalisasi }\end{array}$ & \multicolumn{2}{|c|}{$\begin{array}{l}|X|=\sqrt{90}^{2}+79^{2}+74^{2}+10^{2}+75^{2} \\
|X|=159,818 \\
R 1=0,563 \text { R2=0,49 R3=0,463 R4=0,062 R5=0,469 }\end{array}$} \\
\hline $\begin{array}{l}\text { Matriks keputusan } \\
\text { yang ternormalisasi } \\
\text { terbobot }\end{array}$ & $\begin{array}{l}\mathrm{Y}_{1}=\mathrm{W}_{1} * \mathrm{R}_{1}=30 \% * 0,563=0,084 \\
\mathrm{Y}_{3}=\mathrm{W}_{3} * \mathrm{R}_{3}=15 \% * 0,463=0,092 \\
\mathrm{Y}_{5}=\mathrm{W}_{5} * \mathrm{R}_{5}=20 \% * 0,469=0,093\end{array}$ & $\begin{array}{l}\mathrm{Y}_{2}=\mathrm{W}_{2} * \mathrm{R}_{2}=20 \% * 0,494=0,074 \\
\mathrm{Y}_{4}=\mathrm{W}_{4} * \mathrm{R}_{4}=15 \% * 0,062=0,018\end{array}$ \\
\hline $\begin{array}{l}\text { Solusi ideal positif dan } \\
\text { solusi ideal negatif }\end{array}$ & $\begin{aligned} \mathrm{y}^{+} & =\max \{0,084,0,074,0,092,0,018,0,0 \\
\mathrm{y}^{-} & =\min \{0,084,0,074,0,092,0,018,0,09\end{aligned}$ & $\begin{array}{l}3\}=0,093=A^{+} \\
3\}=0,018=A^{-}\end{array}$ \\
\hline \multicolumn{2}{|c|}{$\begin{array}{l}\text { Jarak antara nilai setiap alternatif dengan matriks solusi } \\
\text { ideal positif }\left(\mathrm{D}^{+}\right) \text {dan matriks solusi ideal negatif }\left(\mathrm{D}^{-}\right) \text {. }\end{array}$} & $\begin{array}{l}\mathrm{D}^{+}=\sqrt{0,093}=0,304 \\
\mathrm{D}^{-}=\sqrt{0,018}=0,134\end{array}$ \\
\hline Nilai preferensi -V & & $\mathrm{V}=\frac{\mathrm{D}^{-}}{\mathrm{D}^{-}+\mathrm{D}^{+}}=0,30$ \\
\hline
\end{tabular}

Nilai $\mathrm{V}$ yang lebih besar menunjukan alternatif yang dipilih sebagai yang terbaik, hasil $\mathrm{V}$ data 1 $=0,371, \mathrm{~V}$ data $2=0,371, \mathrm{~V}$ data $3=0,438, \mathrm{~V}$ data $4=0,440, \mathrm{~V}$ data $5=0,30$.

Menu input data calon guru terbaik berfungsi sebagai wadah untuk melakukan masukan input bagi sistem pendukung keputusan untuk memasukkan data-data calon guru dengan tujuan untuk mempermudah kepala sekolah dalam melihat data calon guru terbaik pada SMP Tri Sakti Lubuk Pakam, Gambar 4.

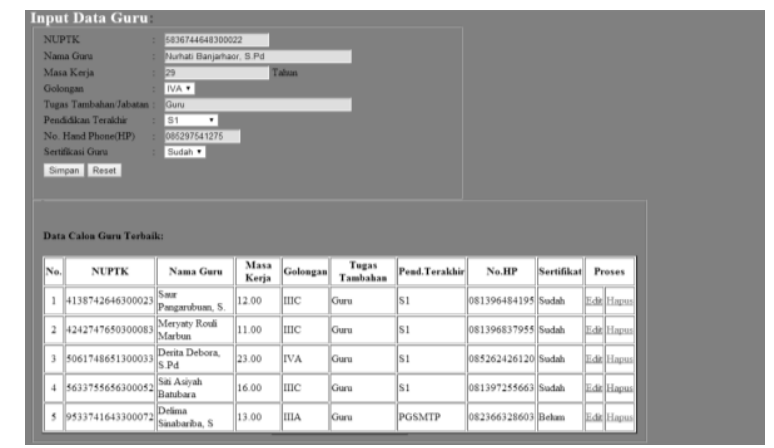

Gambar 4 : Menu Input Data Calon Guru Terbaik

Form proses penilaian metode TOPSIS berfungsi untuk memproses data-data calon guru menjadi guru terbaik, Gambar 5. 


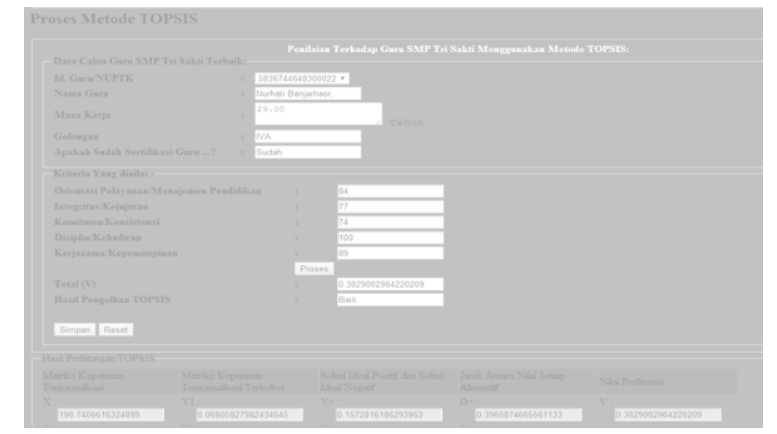

Gambar 5 : Form Proses Penilaian Dengan Metode TOPSIS

\section{Kesimpulan}

Setelah hasil penelitian ini diimplementasikan sesuai dengan metode yang dipilih untuk memperoleh calon guru terbaik maka diperoleh kesimpulan sebagai berikut:

1. Sistem pendukung keputusan yang dibangun dapat berfungsi dengan baik dan benar untuk menentukan calon guru terbaik, Calon guru terbaik-1 (pertama) yaitu calon dengan nilai preferensi $\mathrm{V}_{4}=0,440$, Calon guru terbaik-2 (kedua) dengan nilai preferensi V3 $=0,438$, Calon guru terbaik-3 (ketiga) dengan nilai preferensi $\mathrm{V}_{2}=0,371$.

2. Aplikasi yang dirancang dapat melakukan proses perhitungan TOPSIS secara otomatis untuk menunjang pengambilan keputusan penilaian guru terbaik.

\section{Referensi}

[1] Ahmad Abdul Chamid, "Penerapan Metode Topsis Untuk Menentukan Prioritas Kondisi Rumah", Jurnal SIMETRIS, Vol 7 No 2 Hal : 537-544, November 2016.

[2] Meri Azmi, Yance Sonatha, Rasyidah, "Pemanfaatan Sistem Pendukung Keputusan Untuk Penentuan Alokasi Dana Kegiatan (Studi Kasus Unit Kegiatan Mahasiswa Politeknik Negeri Padang)", Jurnal Momentum, Vol.16 No.1. Hal: 74-83, Februari 2014.

[3] Amelia Nur Fitriana, Harliana, Handaru, "Sistem Pendukung Keputusan Untuk Menentukan Prestasi Akademik Siswa dengan Metode TOPSIS", Citec Journal, Vol. 2, No. 2, hal 153-164, Februari 2015April 2015.

[4] Ma'ruf, "Pengembangan Sistem Pendukung Keputusan Pemilihan Supplier Menggunakan Metode Topsis Pada Perusahaan Furniture", Prosiding Seminar Nasional Ekonomi dan Bisnis \& Call For Paper FEB UMSIDA hal 287-304, 2016.

[5] ASS, Yogi Kurnia, Arjon Samuel Sitio, "Penilaian Kinerja Guru Menggunakan Metode Topsis",JSAI (Journal Scientific and Applied of Informatics), Vol 1 No 3, hal 70-75, Oktober 2018.

[6] Candra Surya, "Penilaian Kinerja Dosen Menggunakan Metode TOPSIS (Studi Kasus : Amik Mitra Gama)", JURNAL RESTI (Rekayasa Sistem dan Teknologi Informasi), Vol. 2 No. 1 hal 322-329. 2018.

[7] Erik Kurniawan, Hindayat i Must afidah dan Anis Shofiyani, "Metode TOPSIS untuk Menentukan Penerimaan Mahasiswa Baru Pendidikan Dokter di Universitas Muhammadiyah Purwokerto, Jurnal Juita, vol III, no. 4 Tahun 2015.

[8] Petir Papilo1, Taufik Djatna, Yandra Arkeman, Marimin, "Penerapan Fuzzy TOPSIS dalam Penentuan Lokasi Kawasan Pengembangan Rantai Pasok Bioenergi Kelapa Sawit”, Agritech, 38 (1) hal. 79-87, Tahun 2018. 